\title{
Nadrian C. (Ned) Seeman (1945-2021)
}

\author{
Ned Seeman, pioneer of the field of structural DNA nanotechnology, passed away on November 16, 2021.
}

$\mathrm{N}$ adrian C. (Ned) Seeman was the first to realize and demonstrate that DNA, apart from its natural functions, could be used as a structural frame to design objects and devices on the scale of nanometres. He was a consummate scientist in the purest sense, envisioning transformative, long-term objectives, parsing them, and pursuing them deliberately over the course of his career. On a personal level, he was keenly intelligent and insightful regarding both science and politics, and deeply appreciative of art and humanities. His communications could be bitingly articulate and could be as profane as they were profound. Yet he was a staunch defender and dedicated mentor of students and young faculty. His astounding memory allowed him to pull up obscure facts critical to projects as well as recommendations of not only restaurants but preferred menu items in many cities around the world.

Seeman was born in Chicago on 16 December 1945. He earned a bachelor of science degree from the University of Chicago (1966) and a PhD in crystallography/biochemistry from the University of Pittsburgh (1970). He did postdoctoral training at Columbia University and at MIT. At MIT, he published several papers that helped to define the structure of RNA. After starting his professional career at SUNY Albany as a crystallographer, Seeman joined the faculty at NYU Department of Chemistry in 1988. His own description of his education and career path was often colourful: he quoted Mark Twain in describing his undergraduate days, saying "I didn't let college interfere with my education." When talking about his time in Albany, he would never fail to mention that it lasted " 3,983 days".

A 'Sputnik kid', Seeman was influenced by his high-school biology teacher who introduced him to the structure of matter and biology. Initially a pre-med student and biochemistry major at the University of Chicago, he was frustrated with the focus at that time on metabolic pathways. Deeply interested in mathematics, he switched to physical chemistry. He didn't begin to excel in science until he began graduate work in crystallography at the University of Pittsburgh. There he was able to cultivate his love for 3D structure and symmetry that dominated his research for the rest of his career. His interest in biology

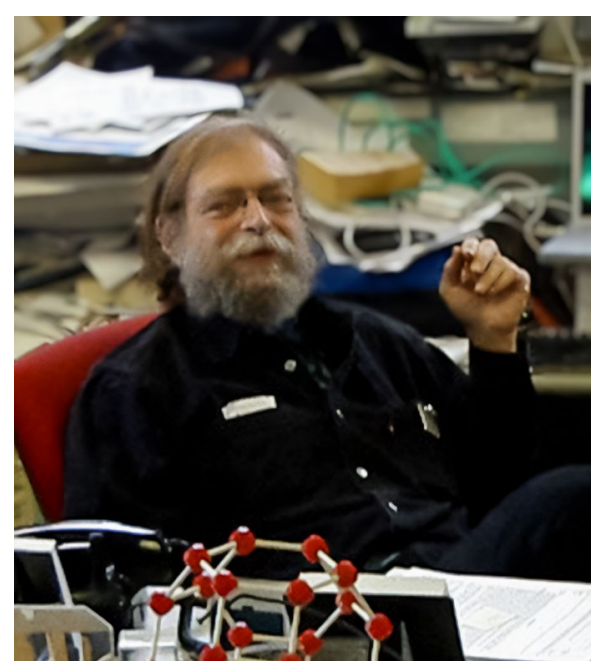

Credit: Photo by James Canary

led him to macromolecular crystallography, and he flourished as a postdoc in the lab of Alex Rich.

As an Assistant Professor, Seeman continued to grapple with macromolecular crystallization and the phase problem in solving molecular structures from crystal diffraction. This problem, together with his interest in art, and especially symmetry, led to his inspiration for periodic DNA structures. One afternoon, he realized that Escher's woodcut, Depth, suggested a possible strategy. Use of a defined DNA crystal lattice able to encapsulate proteins or other molecules would allow solutions to otherwise intractable crystallographic structures. Over the following 30 years, he would develop the techniques needed to achieve this vision. The field of structural DNA nanotechnology grew out of the rationale and techniques that Seeman developed for this crystallography problem; and it is this area that is most widely recognized and appreciated today. Fully 29 years after that afternoon in the Albany campus pub, he and co-workers realized the solution of a crystal structure of a designed 3D lattice of DNA at high resolution.

Seeman's work represents a pinnacle of creativity and accomplishment in molecular science. His realization of molecular expression of topological objects is unparalleled in any other discipline. He constructed a variety of molecular machines, including 'walkers' that could move in designed pathways on DNA trajectories, and ultimately a DNA assembly line that picked up and delivered cargo. In recent work, he began to use these tools to assemble nanoelectronic structures, in which products are built from components that are no larger than individual molecules.

His work has attracted such interest that it has become a field in its own right; the field of structural DNA nanotechnology has grown to include more than 250 laboratories around the world. In this larger community, applications have been made in diverse areas including DNA-based computation, biomedical research, nanoelectronics, and photonics. Largely overlooked by traditional scientific subdisciplines, Seeman created his own. As part of this effort, he founded the International Society for Nanoscale Science, Computation, and Engineering and served as its first president.

He has been recognized by many awards, including the Kavli Prize in Nanoscience from the Norwegian Academy of Science and Letters, the American Chemical Society's Nichols Medal, the Sidhu Award from the Pittsburgh Diffraction Society, a Popular Science Magazine Science and Technology Award, the Feynman Prize in Nanotechnology, a Discover Magazine Emerging Technology Award, the Einstein Professorship of the Chinese Academy of Sciences, the Jagadish Chandra Bose Triennial Gold Medal, and the Benjamin Franklin Medal in Chemistry, among many others. He was an elected member of the American Academy of Arts and Sciences and fellow of the American Association for the Advancement of Science.

Science rarely sees a creative genius like Ned Seeman. His creations at the nexus of biophysics, chemistry, and mathematics gave rise to a new field of research that promises transformative contributions to nanoscale technology. With a rugged exterior, he was a gentle giant, a caring and giving person who will be sorely missed.

\footnotetext{
James W. Canary ${ }^{1 凶}$ and Hao Yan ${ }^{2 凶}$

${ }^{1}$ New York University, New York, NY, USA.

${ }^{2}$ Biodesign Institute, Arizona State University, Tempe, AZ, USA.

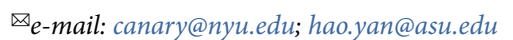

Published online: 10 February 2022

https://doi.org/10.1038/s41565-021-01065-1 